\title{
CANCER TESTICULAR: ESTUDIO DE EXTENSION CON TC DE CUERPO ENTERO
}

\author{
Drs. Jaime Schwaner $C^{(1)}$, Pablo Giacaman $G^{(1)}$, Edgardo San Martín $M^{(1)}$, Francisco Sanhueza $U^{(1)}$, \\ Cristián Fuentes $L^{(1)}$, Alfred Pugh $M^{(2)}$, Esteban Arias ${ }^{(2)}$, Jorge Madariaga $B^{(3)}$.
}

1. Servicio de Imagenología. Hospital Clínico Regional Concepción. Universidad de Concepción.

2. Servicio de Urología, Hospital Clínico Regional Concepción.

3. Servicio de Anatomía Patológica, Universidad de Concepción.

\begin{abstract}
Today testicular cancer has good treatment and long-term survival. Thorax, abdomen and pelvis computerized tomography especially helical technique is the most important tool to evaluate dissemination. We analyzed retrospectively 85 patients studied in the Hospital Regional de Concepción between 20022005 with testicular tumors whom had complete laboratory and TC helical evaluation and correlated local invasion detected in surgery with CT staging for estimate prognostic survival in agree with European consensus on diagnosis and treatment of germ cell cancer. The mean age at the time of diagnosis was 31 years (Range 19-57). Forty three were seminoma and 42 non seminomatous tumors. Staging demonstrated 43 stage I, 20 stage II and 22 stage III. Our prognostic groups were different to other series with $71 \%$ of patient's good prognostic, $24 \%$ intermediate and only 5\% bad prognostic (non seminomatous tumors). We think that the new technology helical can obviate chest $x$-ray in the initial evaluation of these patients.
\end{abstract}

Key words: Adenopathy, CT, Metastases, Testicular cancer.

Resumen: Introducción. La evaluación con tomografía computada (TC) de tórax, abdomen y pelvis de pacientes con cáncer testicular es importante para determinar la extensión de su enfermedad y los controles post-tratamiento. Quienes presentan metástasis son candidatos a quimioterapia 10 que permite una supervivencia mayor al $80 \%$ en el largo plazo. Objetivos: Estimar la frecuencia de invasión regional y a distancia usando TC de cuerpo

\footnotetext{
Schwaner J. Cáncer testicular: Estudio de extensión con TC de cuerpo entero. Rev Chil Radiol 2005; 11: 193-200. Correspondencia: Dr. Jaime Schwaner C.

Servicio de Imagenología. Hospital Guillermo Grant B. Concepción.

Email:jschwaner@terra.cl
}

entero en los diferentes tipos histológicos de cáncer testicular y correlacionar con las pautas de pronóstico del Consenso Europeo para el diagnóstico y tratamiento de este tipo de cáncer. Material y método: Nuestro estudio incluyó 85 pacientes con cáncer testicular diagnosticados por clínica y estudio ecotomográfico en el Hospital Regional de Concepción entre los años 2002 a 2005. A todos ellos se les realizó TC tórax-abdomen-pelvis para estadificación. Los estudios fueron realizados con escáner helicoidal usando en forma rutinaria contraste oral y endovenoso no iónico en dosis estándar de $150 \mathrm{~m} /$. Las imágenes axiales y reconstruidas fueron analizadas por radiólogos del servicio de imagenología. Se consigno la presencia, y ubicación de linfonódulos metastásicos y metástasis. El estudio histológico del tumor testicular se relacionó con su estadificación según la TC de cuerpo entero, siendo luego agrupados en grupos pronósticos para estimar probabilidad de sobrevida. Resultados: En nuestra casuística, los tumores testiculares afectan a varones con un promedio de edad de 31 años y en un rango de 19 a 57 años. Según TNM (AJCC staging system 1997): en etapa I estaban 43 pacientes (50,6\%), en etapa II 20 (23,5\%) y en etapa III 22 (25,9\%). En 43 pacientes el tipo histológico fue seminoma clásico puro y en 42 noseminoma. De los 42 pacientes con tumores no seminomas: cinco presentaron carcinoma embrionario puro y 20 mixto, coriocarcinoma mixto se observo en seis, teratoma maduro en siete y en un paciente teratoma inmaduro. Sólo tres casos presentaron teratocarcinomas. Conclusión: La proporción de seminomas y no seminomas se correlaciona con la literatura nacional e internacional, excepto con un estudio del grupo español. Nuestros grupos pronósticos difieren con los del Consenso Europeo para el diagnóstico y tratamiento del tumor testicular. Pensamos que la Rx de tórax se podría obviar en la evaluación inicial y usar solamente TC 
de tórax, abdomen y pelvis en los centros que cuenten con tecnología helicoidal, ya que de esta forma evitamos una reevaluación en los casos de radiografía sospechosa o con signos de diseminación secundaria, usando una sola inyección de contraste, apnea y tiempo de examen.

Palabras clave: Adenopatías retroperitoneales, Cáncer testicular, Estadificación, Metástasis, TC.

\section{Introducción}

El cáncer testicular, aunque relativamente raro, es el tumor maligno más común en hombres jóvenes entre los 15-35 años, es una de las neoplasias sólidas más curables y sirve como ejemplo para el tratamiento multimodal de tumores malignos. La mejoría en la supervivencia es resultado de la combinación de técnicas de diagnóstico eficaces, buenos marcadores tumorales, regímenes quimioterapéuticos con multidrogas y modificaciones en la técnica quirúrgica que han conducido a una disminución de la mortalidad de más del $50 \%$ antes de 1970 a menos de $5 \%$ de $1997^{(12)}$.

La Sociedad Americana del Cáncer estima que durante el 2005, se diagnosticarán en los Estados Unidos unos 8.010 nuevos casos de cáncer del testículo, calculándose que unos 390 hombres morirán por esta causa. En Chile se diagnosticarán 1.960 casos nuevos en el año 2005 y se calcula que morirán aproximadamente 102 pacientes $^{(20)}$. El índice de cáncer del testículo ha aumentando en muchos países, incluyendo los Estados Unidos. Dicho incremento, en su mayoría es en base a seminomas, no identificándose los motivos.

Es una neoplasia que se asocia con los marcadores tumorales: Beta-gonadotrofina coriónica (B-CG), alfa-fetoproteína (AFP) y láctico deshidrogenada (LDH). Ellos permiten un seguimiento y una intervención precoz en el curso de la enfermedad.

Características adicionales de los tumores testiculares que favorecen su terapéutica son su sensibilidad a la radioterapia y a una amplia variedad de agentes quimioterápicos. También la capacidad para la diferenciación en formas histológicas menos agresivas, índice de crecimiento rápido, predictivo patrón de diseminación sistémico y ocurrencia en individuos jóvenes, sin enfermedad asociada, que puedan tolerar un tratamiento multimodal.

Tienden a metastizar por el sistema linfático y la comprensión de su distribución y patrón de extensión linfática es de gran ayuda para interpretar los hallazgos en tomografía computada (TC).

La evaluación de los pacientes con cáncer testicular con TC de tórax, abdomen y pelvis es importante para determinar la extensión de la enfermedad y controlar el tratamiento evaluando los efectos de la terapia, cuantificando la reducción o desaparición de las masas.

\section{Material y método}

Revisión retrospectiva con análisis de fichas clínicas, biopsias e informes de TC de tórax, abdomen y pelvis. Se analizaron 200 pacientes con diagnóstico de cáncer testicular en el período de marzo 2002 a marzo 2005 en el Hospital Regional de Concepción, de ellos 85 cumplían los criterios de inclusión que fueron: 1) Estudio histológico disponible del testículo comprometido. 2) Marcadores tumorales (AFP, B-HCG, LDH) al momento del diagnóstico. 3) TC de tórax, abdomen y pelvis al diagnóstico.

Técnica de examen: Se realizó TC de tórax, abdomen y pelvis, previo consentimiento informado y encuesta para uso de medio de contraste iodado endovenoso. Los estudios fueron realizados en nuestra institución con escáner helicoidal (Philips medical systems Nederland, modelo Secura) en uso desde marzo del año 2002. En forma rutinaria se usó contraste oral y se inyectó contraste endovenoso no iónico (loversol: Optiray 320 y iohexol: Omnipaque) en dosis estándar de $150 \mathrm{ml}$, a través de un acceso venoso $18 \mathrm{G}$, a $3 \mathrm{ml} / \mathrm{seg}$, con inyectora automática (En-Visión CT; Medrad, Indianola, PA), generalmente en vena antecubital. El tiempo de delayfue de 30 segundos comenzando por el tórax, para examinar hígado a los $50-60 \mathrm{seg}$. Los cortes fueron de $7 \mathrm{~mm}$ de grosor, con reconstrucción de $7 \mathrm{~mm}$ y Pitch 1,5 con una rotación del gantry de 0,7 segundos; usando $240 \mathrm{mAs}$ y $120 \mathrm{kVp}$. El barrido se efectuó desde el ápex pulmonar hasta el perine durante una sola apnea.

Se efectuaron TC cerebrales en dos pacientes con sintomatología focal neurológica.

Evaluación de las imágenes: Las imágenes axiales y reconstruidas fueron analizadas por cuatro radiólogos del servicio de imagenología del equipo de cuerpo. Se consignó la presencia de linfonódulos y metástasis a distancia midiendo el diámetro transverso mínimo en milímetros y su ubicación. Cuando un paciente tenía un linfonódulo menor a $5 \mathrm{~mm}$ o no se encontró, fue considerado normal. Valores sobre $6 \mathrm{~mm}$ en el eje axial fueron considerados patológicos. A todos ellos se les realizó estudio histológico de su tumor testicular y luego lo relacionamos con su estadificación según la TC de cuerpo entero.

\section{Resultados}

Los 85 pacientes considerados en el estudio, presentan un rango de edad entre 17 a 57 años con un promedio de 31 años.

La distribución de los tumores testiculares fue 43 casos seminoma clásico puro y 42 no seminomas. De estos últimos cinco presentaron carcinoma embrionario puro y 20 tipo mixto, seis coriocarcinoma mixto, siete teratoma maduro y un paciente teratoma inmaduro. Sólo tres casos 
presentaron teratocarcinomas. En nuestro estudio no tuvimos tumores estromales, ni metastáticos (Tabla I).

Comparamos los tipos histológicos de cáncer testicular según Mostofi y nuestros resultados (Tabla II).

En los pacientes con seminoma, 10 presentaron compromiso en tórax, 17 en región abdominal y cuatro en región pelviana. Los predictores más importantes de compromiso secundario son la presencia de invasión en el tumor primario de linfáticos, rete testis, túnica albugínea, túnica vaginalis, epidídimo, cordón, escroto y presencia de sinciotrofoblasto. De los casos con metástasis en tórax cuatro $(9 \%)$ tenían signos de invasión local en el estudio histológico del testículo; de los con metástasis abdominales 12 (28\%) y dos (5\%) de los con metástasis pelviana.

En los pacientes con cáncer testicular no seminomas, dos presentaron metástasis cerebral y tenían signos de invasión local en el tumor testicular. Los pacientes con compromiso en el tórax fueron 11 ; de ellos seis (14\%) tenían signos de invasión local; de 19 casos con metástasis en el abdomen 11 (26\%) tenían signos de invasión local y de dos pacientes con metástasis pelviana uno $(2 \%)$ tenía invasión local testicular (Tabla III).

Según su presentación TNM (AJCC staging system 1997): en etapa I estaban la mayoría de los pacientes $43(50,6 \%)$, en etapa II había 20 pacientes $(23,5 \%)$ y en etapa III, 22 pacientes que representa un $25,9 \%$ del total (Tabla IV).

De acuerdo a la clasificación de grupos pronóstico de la International Germ Cell Cancer

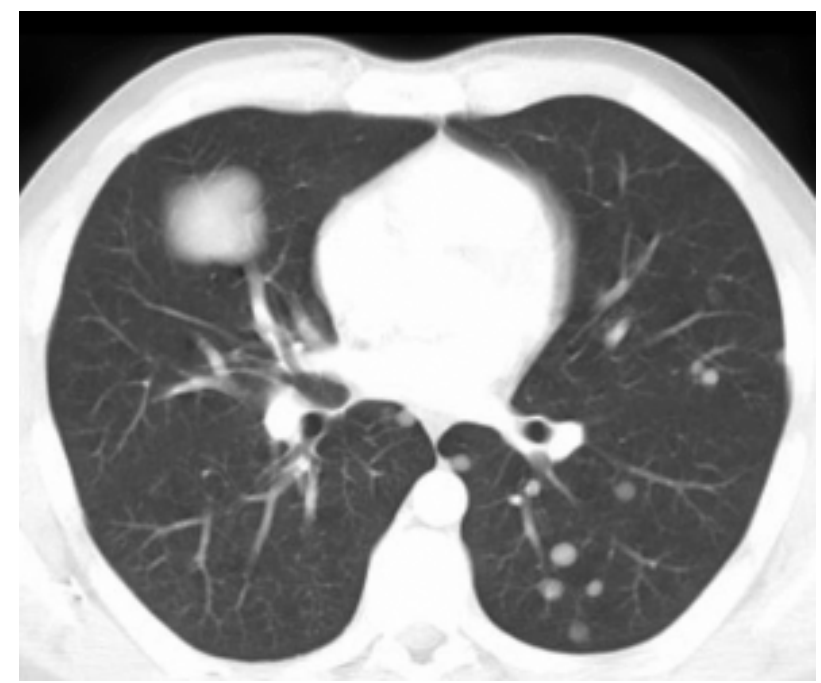

Figura 1. TC de tórax en paciente de 23 años con compromiso secundario pulmonar a tumor testicular. Se evidencian múltiples nódulos, correspondientes a metástasis.
Collaborative Group, el $71 \%$ de los pacientes presentaron buen pronóstico (13 seminomas y 17 no seminomas), $24 \%$ presentaron pronóstico intermedio (siete seminomas y tres no seminomas), y $5 \%$ mal pronóstico, correspondiendo a dos pacientes no seminomas exclusivamente (Tabla V).

En las figuras 1-4 se ilustran hallazgos de diseminación tumoral secundaria en pulmón y linfonódulos. Se ilustra además la relación de los grandes vasos con los linfonódulos a nivel retroperitoneal (Figura 5).

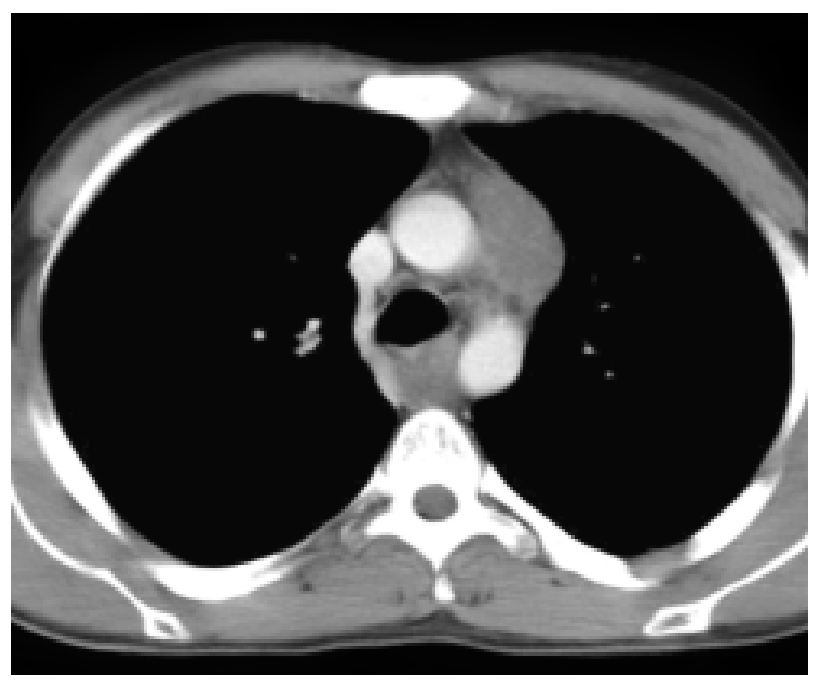

Figura 2. TC de tórax en paciente 21 años con tumor testicular y compromiso de linfonódulos mediastínicos alrededor del cayado aórtico.

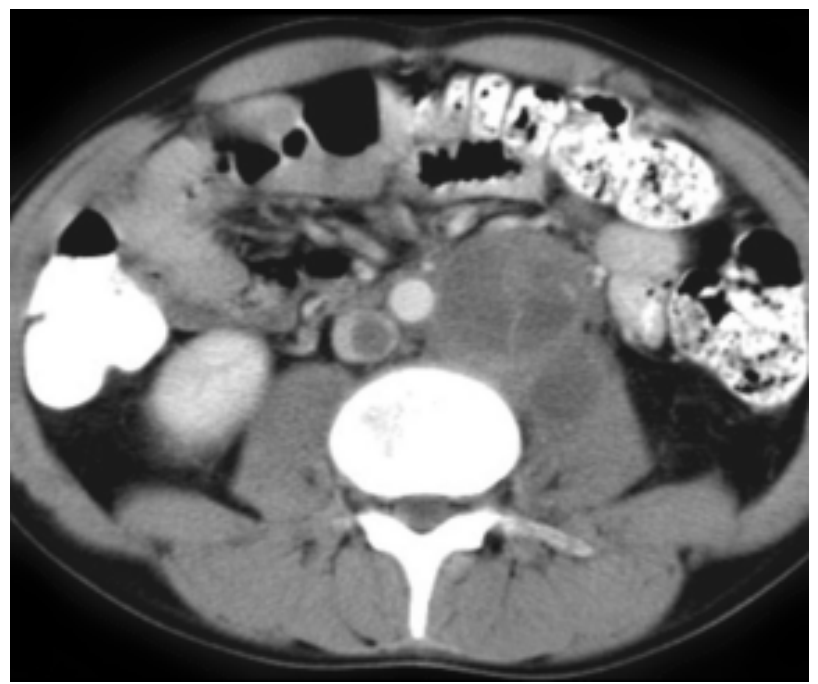

Figura 3 a. TC abdominal en paciente de 21 años demostrando compromiso de linfonódulos retroperitoneales, que desplazan la aorta. Obsérvese además, trombosis tumoral en vena cava inferior. 


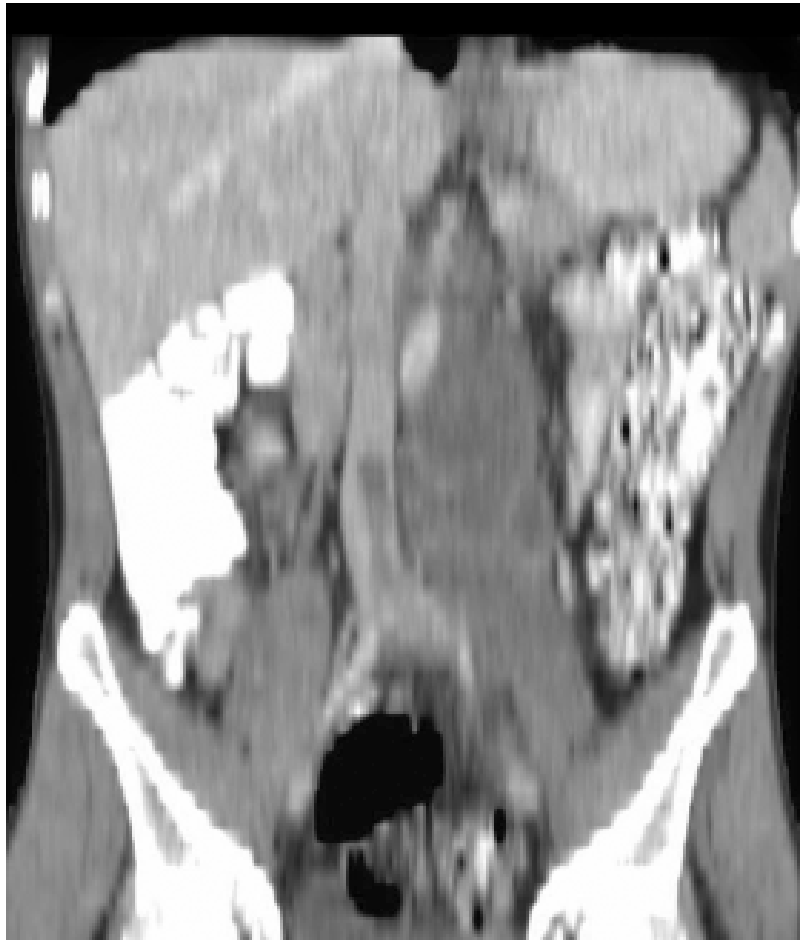

Figura 3. b) Reconstrucción coronal del mismo paciente.

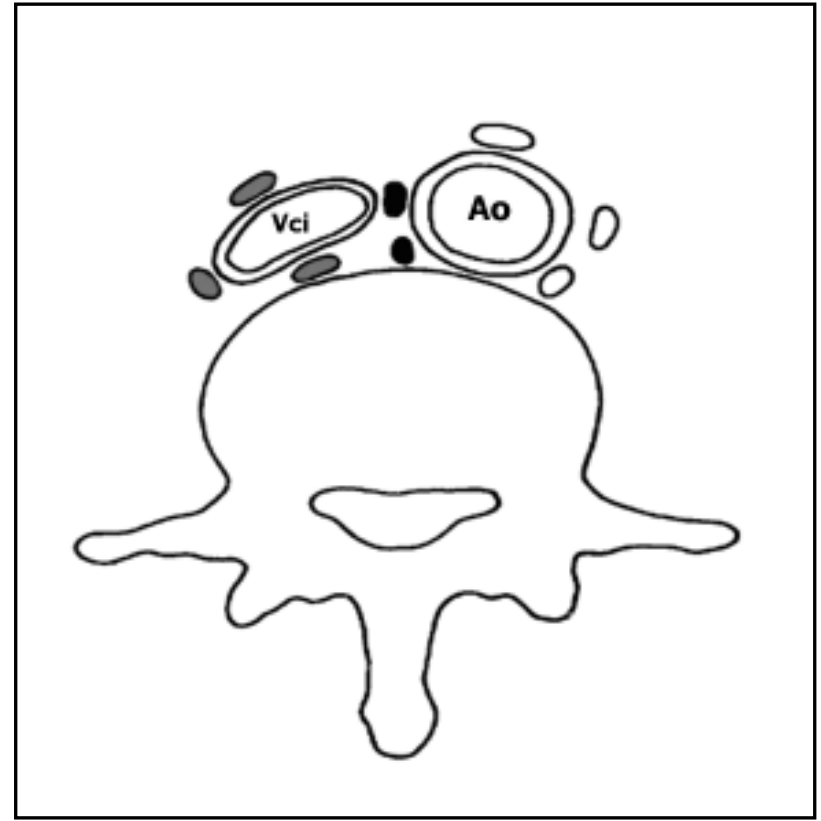

Figura 5. Esquema de linfonódulos retroperitoneales. Ao: Aorta. Vci: Vena cava inferior. En blanco los linfonódulos peri-aórticos, en negro los intercavos-aórticos y en gris los peri-cávicos.
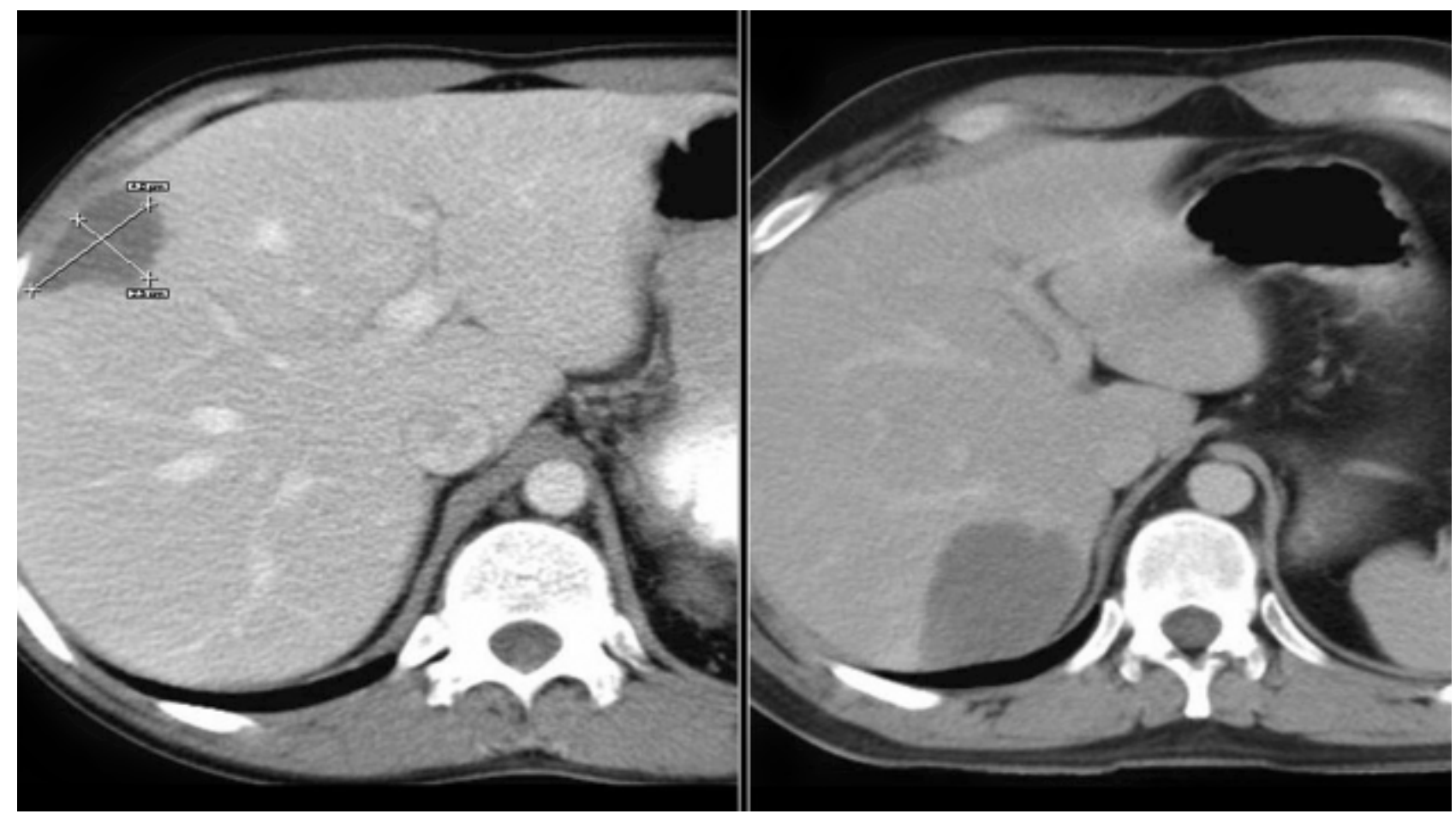

Figura 4 a,b. Metástasis hepáticas de tumor testicular. a): Paciente de 37 años con lesión nodular hipodensa hepática. b) Paciente de 21 años con lesión nodular metastásica hepática, más aumento de los marcadores tumorales en forma progresiva. La lesión fue resecada comprobándose el diagnostico. 
Tabla I. Distribución de tumores testiculares según tipo histológico.

\begin{tabular}{|lrr|} 
Seminomas Clásico puro & $\mathbf{4 3}$ & $\mathbf{( 5 0 , 5 8 \% )}$ \\
No seminomas & $\mathbf{4 2}$ & $\mathbf{( 4 9 , 4 2 \% )}$ \\
Carcinoma Embrionario & 5 & $(12,0 \%)$ \\
Carcinoma Embrionario mixto & 20 & $(47,6 \%)$ \\
Coriocarcinoma mixto & 6 & $(14,3 \%)$ \\
Teratoma maduro & 7 & $(16,7 \%)$ \\
Teratoma inmaduro & 1 & $(2,4 \%)$ \\
Teratocarcinoma & 3 & $(7,0 \%)$ \\
Total & & \\
& $\mathbf{8 5}$ & \\
\hline
\end{tabular}

Tabla II.Tabla comparativa de frecuencia de acuerdo a tipo histológico según Mostofi (1973) y nuestro grupo de estudio.

\begin{tabular}{|lrc|}
\hline Tipo histológico & Mostofi & HRC * \\
Seminoma & $\mathbf{3 0 - 6 0 \%}$ & $\mathbf{4 3} \mathbf{( 5 0 . 6 \% )}$ \\
Clásico & $82-85 \%$ & $43(100 \%)$ \\
Anaplástico & $5-10 \%$ & 0 \\
Espermatocítico & $2-12 \%$ & 0 \\
& & \\
No seminoma & $\mathbf{4 0 \%}$ & $\mathbf{4 2}(\mathbf{4 9 , 4} \%)$ \\
Carcinoma embrionario & $3-4 \%$ & 5 \\
Coriocarcinoma & $1 \%$ & $(-)$ \\
Teratocarcinoma & $5-10 \%$ & 3 \\
Teratoma & \multicolumn{2}{c}{} \\
Mixtos & $\mathbf{6 0 \%}$ & $\mathbf{2 6}(\mathbf{3 0} \%)$ \\
* HRC: Hospital Regional de Concepción. \\
\hline
\end{tabular}

Tabla III. Tipos de tumores testiculares y metástasis ganglionares o de órganos, en relación a invasión local.

\begin{tabular}{lccccc|}
\hline Tumor testicular & Cerebro & Tórax & Abdomen & Pelvis & $\%$ \\
Seminoma sin invasión. & 0 & 6 & 5 & 2 & $30,3 \%(13)$ \\
Seminoma con invasión* & 0 & 4 & 12 & 2 & $41,9 \%(18)$ \\
No seminoma sin invasión. & 0 & 5 & 8 & 1 & $33,3 \%(14)$ \\
No seminoma con invasión* & 2 & 6 & 11 & 1 & $47,6 \%(20)$
\end{tabular}

*Invasión: Se refiere al compromiso de linfáticos, rete testis, túnica albugínea, túnica vaginalis, epidídimo, cordón o escroto en el tumor primario y presencia de sinciotrofoflasto.

Tabla IV. Distribución porcentual de estadio según clasificación TNM (AJCC Staging System 1997).

\begin{tabular}{lll} 
Estadio & No & Porcentaje (\%) \\
\hline Estadio I & 43 & $50,6 \%$ \\
Estadio II & 20 & $23,5 \%$ \\
Estadio III & 22 & $25,9 \%$ \\
\hline
\end{tabular}

Tabla V. Clasificación de los 42 pacientes con metástasis en grupos pronósticos según la International Germ Cell Cancer Collaborative Group.

\begin{tabular}{lccccr|} 
Pronóstico & $\begin{array}{c}\text { Seminoma } \\
\text { Estadio II }\end{array}$ & $\begin{array}{l}\text { Seminoma } \\
\text { Estadio III }\end{array}$ & $\begin{array}{l}\text { No Seminoma } \\
\text { Estadio II }\end{array}$ & $\begin{array}{c}\text { No Seminoma } \\
\text { Estadio III }\end{array}$ & Total \\
Bueno & 13 & 0 & 9 & 8 & $30(71 \%)$ \\
Intermedio & 7 & 0 & 3 & 0 & $10(24 \%)$ \\
Malo & 0 & 0 & 0 & 2 & 2 \\
Total & 20 & 0 & 12 & 10 & 42 \\
\hline
\end{tabular}




\section{Discusión}

En el estudio de estadificación del cáncer testicular se han usado diferentes métodos de imágenes a través del tiempo, actualmente se recomienda TC de tórax, abdomen y pelvis con contraste endovenoso y por vía oral.

La TC de tórax se podría omitir en pacientes con seminoma testicular que no presentan masa retroperitoneal ${ }^{(1,2,20)}$. Sin embargo, se debe considerar que para la evaluación del pulmón y mediastino, es más sensible que la $R x$ de tórax ${ }^{(3,4)}$ y que son los pulmones el primer sitio de ubicación metastásica extralinfático, es esta técnica capaz de detectar metástasis en aproximadamente 12 a $27 \%$ de los pacientes que tienen $\mathrm{Rx}$ negativas ${ }^{(5,6)}$ y además detecta múltiples nódulos en pacientes que muestran un nódulo solitario en la $R x$ de tórax ${ }^{(5)}$, es también más sensible para detectar adenopatías mediastínicas ${ }^{(21)}$. Sin embargo, algunas publicaciones destacan que nódulos pulmonares y pleurales menores de un centímetro pueden representar un falso positivo(7-9).

Las exploraciónes con TC de abdomen y pelvis pueden dar falsos negativos en hasta $30 \%$ de los casos debido a las dificultades en la interpretación de los linfonódulos basados sólo en la morfología ${ }^{\left({ }^{10)}\right.}$. El informe radiológico debe indicar una descripción detallada de la localización, número y tamaño de ellos.

La TC sigue siendo el medio más eficaz para identificar el compromiso retroperitoneal y sustituyó a la linfangiografia bipedal como el procedimiento de elección, proporciona una estimación tridimensional del tamaño tumoral y del compromiso de partes blandas y órganos, además da una visión del espacio retrocrural y región paraaórtica sobre los pilares del diafragma, que constituyen un sitio importante de metástasis. Sin embargo, no es lo suficientemente exacta para distinguir fibrosis o malignidad usando sólo criterios del tamaño ${ }^{(11)}$ lo que pudo constituir una fuente de error en nuestra interpretación de compromiso metastático.

La exactitud para la TC es del $70 \%$ a $90 \%$, con una sensibilidad del $40 \%$ a $60 \%$ y una especificidad que se acerca a 100\%. En general su sensibilidad baja debido a la dificultad para detectar metástasis en linfonódulos de tamaño normal. Al bajar los criterios del tamaño para considerar un linfonódulo patológico de $15 \mathrm{~mm}$ a $5 \mathrm{~mm}$ aumenta la sensibilidad, pero se asocia a una disminución de la especificidad sin cambio significativo en la seguridad total. La TC también detecta metástasis a los órganos extralinfáticos tales como el hígado y el pulmón ${ }^{(12)}$.

Las exploraciones con resonancia magnética (RM) del abdomen y pelvis no proporcionan información adicional en la estadificación del retroperitoneo en pacientes con cáncer de testículo y se debería restringir a quienes los medios de contraste yodados no puedan administrarse ${ }^{(13,14)}$.

La RM es comparable a la TC en la detección de adenopatías retroperitoneales en adultos. Tiene algunas ventajas como lo es su capacidad para distinguir estructuras vasculares de partes blandas sin el uso de contraste yodado. Los linfonódulos medianamente aumentados de tamaño pueden ser difíciles de detectar por TC debido a la gran variabilidad en la localización, diámetro y orientación de las arterias y de las venas pélvicas, especialmente cuando su opacificación no se logra en forma adecuada. Además en algunos casos los linfonódulos pélvicos levemente aumentados de tamaño se pueden confundir con los vasos pelvianos, dado que ambos se pueden contrastar en forma similar, en estos casos la RM presenta indudables ventajas. Las anomalías venosas, venas gonadales prominentes y colaterales pueden simular adenopatías retroperitoneales en TC sin contraste, pero son fácilmente diferenciadas de las estructuras vasculares por $\mathrm{RM}^{(12)}$.

Se ha reportado estudios con el uso de la tomografía por emisión de positrones (PET) en la evaluación de linfonódulos retroperitoneales y sus anormalidades después de quimioterapia en pacientes con el cáncer de testículo. Aparentemente no ha demostrado ventaja evidente sobre la TC principalmente porque tampoco tiene la capacidad para detectar enfermedad nodal microscópica. No hay ensayos clínicos con PET que lo recomienden como parte de la etapificación inicial en forma rutinaria ${ }^{(15-16)}$.

Las exploraciones óseas se deben realizar en pacientes con niveles elevados de fosfatasas alcalinas 0 si hay sospecha clínica de metástasis óseas. Los estudios con imágenes del cerebro con TC o preferiblemente con RM se realizarán frente a sospecha clínica ${ }^{(10)}$. La TC se puede utilizar para confirmar una recurrencia cuando los marcadores tumorales son positivos. Se debe considerar que la gran mayoría de seminomas puros no produce HCG o AFP.

La TC se ha convertido en el procedimiento de elección en el seguimiento de la respuesta a la radioterapia y quimioterapia. Algunas masas retro-peritoneales residuales pueden permanecer incluso después del tratamiento exitoso en carcinomas testiculares metastáticos, ellas pueden representar fibrosis postratamiento o tumor, generalmente en el tipo no-seminomatoso y es imposible distinguirlas con $\mathrm{TC}^{(11-12)}$.

La proporción de tumores testiculares en nuestra serie fue $50,6 \%$ para seminomas y $49,4 \%$ para no seminomas, un estudio nacional previo del Hospital Barros Luco ${ }^{(17)}$, reportó $55 \%$ de seminomas y $45 \%$ no seminomas con una edad promedio de 32 años y siendo la nuestra de 31 años lo que esta en relación a lo descrito por Campbell. Un estudio del Hospital Regional de Temuco ${ }^{(18)}$ comunicó un $50 \%$ de seminomas y $50 \%$ no seminomas con una edad promedio de 34 años. La distribución de tumores seminoma y no seminoma en el grupo español(19) de cáncer de células germinales fue $35,8 \%$ y $64,2 \%$ respectivamente, ellos observaron un valor más alto en los tumores no seminomas, similar a series 
reportadas en Inglaterra, pero diferentes de otras de EE.UU, Canadá, Dinamarca y la nuestra.

Los predictores histológicos a nivel del tumor primario más importantes para metástasis son: La invasión de los linfáticos y presencia de sincio-trofoblasto. En nuestra serie obtuvimos un $63 \%$ de estos predictores en el estudio histológico para seminomas y un $68 \%$ para no seminomas en aquellos pacientes que presentaron metástasis.

Los diferentes grupos pronósticos han sido descritos en la literatura, pero no se usan en forma rutinaria; constituye otra forma para clasificar y estimar sobrevida a cinco años; que en el grupo de buen pronóstico alcanza un $90 \%$, en el intermedio un $80 \%$ y desciende a un $50 \%$ en el grupo de mal pronóstico. En nuestra serie, observamos 30 pacientes $(71 \%)$ en buen pronostico; intermedio 10 (24\%) y mal pronostico $2(5 \%)$. En el estudio del European germ cell cancer consensus group (EGCCCG) ${ }^{(10)}$ tuvieron $56 \%$ de los pacientes en buen pronóstico, $28 \%$ en pronóstico intermedio y $16 \%$ con mal pronostico. Permanece como desafío el proseguir con el estudio a cinco años para controlar la sobrevida estimada.

Desde 1960 existía una amplia variedad de sistemas de estadificación clínica para seminomas y noseminomas que dificultaban la comparación de diferentes series. Según el estadio o la propagación metastásica, existen tres clasificaciones que se usan internacionalmente, la de Boden-Gibbs, la del Royal Madsen Hospital y la TNM, esta última difundida por la AJCC (The American Joint Committee on Cancer). El año 1997 se decide en consenso internacional usar la TNM junto con marcadores tumorales adicionales (S) para estandarizar los registros, aún no está suficientemente utilizada, lo que mantiene las dificultades para comparar distintos estudios y no encontramos, en revisión de la literatura radiológica nacional e internacional de consulta habitual, trabajos como el nuestro con asociación de imágenes y etapificación TNM-S ${ }^{(20)}$.

En nuestra serie obtuvimos un mayor número de metástasis en cavidad abdominal a diferencia de lo descrito en la literatura que indica un número mayor de lesiones metastásicas en tórax ${ }^{(5,6)}$.

Aunque no fue objetivo del estudio, pensamos que la Rx de tórax se podría obviar en la etapificación de los pacientes con tumor testicular con el estudio de TC de tórax, abdomen y pelvis en los centros que cuenten con tecnología helicoidal, de esta forma evitaremos una nueva evaluación de los casos con radiografía de tórax sospechosa o con signos de diseminación secundaria, usando una única inyección de contraste, apnea y un tiempo único de examen.

\section{Agradecimientos}

Los autores expresan su gratitud a Angélica Iturrieta, por su constante dedicación en mantener al día nuestro registro de tumores testiculares y a nuestros tecnólogos médicos de la unidad de TC del HRC: Ramón Lastra, Elizabeth Moya, María Muñoz, Iván Pizarro, Yasna Pozo y Gina Huarachi por su asistencia en la realización de los exámenes, como en la obtención de las imágenes.

\section{Bibliografía}

1. Gospodarowicz MK, Sturgeon JFG, Jewett MAS. Early stage and advanced seminoma: role of radiation therapy, surgery, and chemotherapy. Semin Oncol 1998; 25: 160-173.

2. White PM, Adamson DJA, Howard GCW et al. Imaging of the thorax in the management of germ cell testicular tumours. Clin Radiol 1999; 54: 207-211.

3. White PM, Howard GC, Best JJ et al. The role of computed tomographic examination of the pelvis in the management of testicular germ cell tumours. Clin Radiol 1997; 52: 124-129.

4. Meyer CA, Conces DJ. Imaging of intrathoracic metastases of non seminomatous germ cell tumors. Chest Surg Clin N Am 2002; 12: 717-738.

5. Nickfeld JP, Michaelis LL, Doppman JL. Suspected pulmonary metastasis: correlation of chest X-ray, whole lung tomography. Cancer 1997; 39: 383-387.

6. Bergman SM, Lippert M, Javadpour N. The value of whole lung tomography in the early detection of metastatic disease in patiens with renal cell carcinoma and testicular tumors. J. Urology 1980; 124: 860-862.

7. Heidenreich A, Sesterhenn IA, Mostofi FK et al. Prognostic factors that identify patients with clinical stage I nonseminomatous germ cell tumors at low risk and high risk for metastasis. Cancer 1998; 83: 10021011.

8. Lashley D, Lowe B. A rational approach to managing stage I nonseminomatous germ cell cancer. Urol Clin North Am 1998; 25: 405-423.

9. Leibovitch I, Foster RS, Kopecky KK et al. Identification of clinical stage A nonseminomatous testis cancer patients at extremely low risk for metastatic disease: a combined approach using quantitative immunohistochemical, histopathologic, and radiologic assessment. J Clin Oncol 1998; 16: 261-268.

10. Schmoll h, Souchon R, Krege S, et al. European consensus on diagnosis and treatment of germ cell cancer: a report of the European germ cell cancer consensus group (EGCCCG).Annals of oncology. 2004; 15: 1377-1399.

11. Lee, Sagel, Stanley, Heiken. Computed tomography body with MRI correlation. Edición 1999; 873-953.

12. Campbell. Tratado de Urología. $8^{a}$ Edición 2003; Capítulo 81.

13. Bellin M, Roy $\mathrm{C}$, Kinkel $\mathrm{K}$ et al. Lymph node metastases: safety and effectiveness of MR imaging with ultrasmall superparamagnetic iron oxide particles: initial clinical experience. Radiology 1998; 207: 799808.

14. Hogeboom WR, Hoekstra HJ, Mooyart EL et al. Magnetic resonance imaging of retroperitoneal lymph node metastases of non-seminomatous germ cell tumors of the testis. Eur J Surg Oncol 1993; 19: 429437.

15. Albers $\mathrm{P}$, Bender $\mathrm{H}$, Yilmaz $\mathrm{H}$ et al. Positron emission tomography in the clinical staging of patients with stage I and II germ cell tumors. Urology 1999; 53: 808-811.

16. Spermon JR, De Geus-Oei LF, Kiemeney LA et al. The role of 18-fluoro-2-deoxyglucose positron emission tomography in initial staging and re-staging after chemotherapy for testicular germ cell tumours. BJU Int 2002; 89: 549-556.

17. Morales $C$, Olivares R, Silva R et al. Cáncer testicular en Servicio de Urología experiencia Hospital Ramón Barros Luco. Revista Chilena de Urología 2003; 68: 71-74. 
18. Gorena M, Cifuentes M, González R et al. Perfil clínico y epidemiológico del cáncer testicular en la IX región. Revista Chilena de Urología 2003; 68: 78-82.

19. Germà-Lluch JR, Garcia del Muro X, Maroto et al. Patrones clínicos y resultados terapéuticos en 1.490 pacientes con tumores testiculares de células germinales: experiencia del grupo español de cáncer de células germinales (GG). European Urology 2002; 42: 553-563.

20. Ministerio de Salud de Chile. Guía Clínica Cáncer de Testículo en personas de 15 años y más. 1st Ed. Santiago: Minsal, 2005.

21. Crowe JK, Brown LR, Muhm JR. Computed tomography of the mediastinum. Radiology 1978; 128: 75- 87. 